\title{
Adsorption of Benzene and Phenolic Derivatives in Monolithic Carbon Aerogels
}

\section{J. C. MORENO-PIRAJÁN ${ }^{\mathrm{a}^{*}}$ and L. GIRALDO ${ }^{\mathrm{b}}$}

${ }^{a}$ Facultad de Ciencias, Departamento de Química, Grupo de Investigación en Sólidos Porosos, Universidad de los Andes, Bogotá, Colombia

${ }^{\mathrm{b}}$ Facultad de Ciencias, Departamento de Química, Universidad Nacional de Colombia

jumoreno@uniandes.edu.co

Received 12 July 2012 / Revised 4 August 2012 / Accepted 16 August 2012

\begin{abstract}
A monolithic carbon aerogel with a specific pore texture was used as benzene adsorbent. Adsorption was carried out under static conditions at $25^{\circ} \mathrm{C}$ and at saturation, an adsorption capacity as high as $0.77 \mathrm{~cm}^{3} \cdot \mathrm{g}^{-1}$ or $837 \mathrm{mg} \cdot \mathrm{g}^{-1}$ was obtained. This work is devoted to the application of carbon aerogels for the removal of hydroquinone, catechol and resorcinol from aqueous solutions. These materials were tested and characterised regarding their morphology, particle size distribution, surface area and porous structure. Equilibrium tests were carried out at different adsorbate concentrations and the experimental data were correlated by means of Langmuir and Freundlich isotherms. The equilibrium data were well described by Langmuir and Freundlich in most cases. The maximum adsorption capacity of the Langmuir model was observed for the adsorption of benzene onto aerogel $(242.33 \mathrm{mg} / \mathrm{g})$, though the most promising results were obtained for toluene adsorption, owing to the greater adsorption energy involved. Comparing these results with other reported results, our carbon aerogel hydrophobics were found to exhibit a remarkable performance for the removal of benzene.
\end{abstract}

Keywords: Carbon aerogels, Benzene adsorption, Phenolic adsorption

\section{Introduction}

The pollution of water by organic compounds remains a serious problem, since wastewater is often released from industrial factories without any effective treatment. Phenolic compounds, which are highly toxic substances that damage human health and aquatic life, are common contaminants in wastewater. Organic compounds and especially phenols and its derivatives are considered as pollutants since they are harmful to organisms even at low concentrations and many of them are recognised as hazardous pollutants. The US Environmental Protection Agency (EPA) has determined $1 \mathrm{mg} \mathrm{L}^{-1}$ as the limit of acceptable phenol content in wastewater. Such contaminated water can cause protein degradation, tissue erosion and paralysis of the central nervous system and can damage the kidney, liver and pancreas $^{1-3}$. It is therefore necessary to remove phenolic compounds from industrial wastewaters. They are widely used in industrial processes for synthesising pharmaceutical 
and petrochemical products. Conventional treatment methods, such as biodegradation, adsorption by activated carbon and chemical oxidation have been proposed for purifying wastewater which contains phenolic compounds ${ }^{1-4}$. Many industries use phenolic materials in their manufacturing processes. Phenol and its derivatives are present in the wastewaters of industries such as coking, pulp mills, paint and dyes, wine distilleries, oil and gasoline, synthetic rubber, textiles, pharmaceuticals, solvent, manufacture of pesticides, paper, wood, etc. ${ }^{4,5}$. The organic compounds contained in these industrial wastewaters are difficult to remove by biological treatment. Other techniques have been developed such as chemical oxidation, solvent extraction and carbon adsorption, designed to decrease the amount of toxic, non-biodegradable organic compounds. The most widely used method for water treatment, however, is the carbon adsorption process because carbonaceous adsorbents have a large surface area, microporous nature, high adsorption capacity, high purity and easy availability ${ }^{2,6,7}$.

Although carbonaceous adsorbents are useful for wastewater treatment, the relatively expensive raw materials such as wood and coal used for their production limit their use in the pollution application sector. Therefore, the possibility of creating carbonaceous materials from cheaper raw materials has been examined. Researchers have proposed the preparation of carbon from apricot shell ${ }^{8}$, oil palm fibre ${ }^{9}$, bamboo $^{10}$, coconut husk $^{11}$ and agricultural waste materials ${ }^{12,13}$. Lignocellulosic materials derived from residues of biomass or from agricultural by-products have been combined with a proper synthetic polymer such as novolac resin, which is also used as binding agent. The specimens formed after curing can be transformed to carbon by appropriate carbonisation ${ }^{12,14}$.

Carbon aerogels are very porous materials with interesting properties such as low density, high surface area, continuous open porosity and electrical conductivity. These materials can be obtained by pyrolysis of organic aerogels, which are prepared by sol-gel polycondensation of certain organic monomers such as resorcinol with formaldehyde. This method was first described by Pekala ${ }^{13,14}$.

Carbon aerogels are adsorbents with considerable potential, since their textural characteristics can be tailored by controlling the concentration, proportion and nature of the reactant and catalyst in the original recipes used and at all preparation steps ${ }^{1-8}$. These novel carbon materials are obtained by carbonisation of organic aerogels, which are generally prepared from resorcinol-formaldehyde mixtures by the sol-gel process. Once obtained, the carbon aerogel can be activated to further develop its porosity. Thus, they can be prepared with large surface area and well-developed porosity.

The aim of this work was to investigate the removal process of the aromatic as solvent benzene, and assessment of hydroquinone, catechol and resorcinol, when dissolved in water. The obtained results are compared with several other studies on the adsorption of benzene ${ }^{15-18}$ with aerogels. As regards the hydroquinone, catechol and resorcinol adsorption capacity of carbon aerogels, no reported data were found in the literature.

\section{Experimental}

The preparation of the carbon aerogels was carried out with a procedure based on Tian and colleagues $^{19}$. CAs were synthesised from resorcinol (R) $(99 \%)$, furfural $(\mathrm{F})(99 \%)$, hexamethylenetetramine (HMTA) (99\%), acetic acid (99.7\%) and anhydrous ethanol (E) (99.5\%) obtained from Sigma-Aldrich (Pty) Ltd, Australia. The proportions of individual raw material were one mole of resorcinol to two moles of furfural, i.e. $\mathrm{R} / \mathrm{F}=0.6$. Initially the molar ratio of R/HMTA was set at 30 according to our previous investigation, reported in 
the literature, for determining the appropriate HMTA reaction conditions to obtain suitable gel networks. The precursors were mixed in $\mathrm{E}$ (molar ratio of $\mathrm{E} / \mathrm{R}=180$ ) followed by magnetic stirring for $6 \mathrm{~h}$ in a sealed container. Acetic acid was used as a catalyst by dropwise addition to the precursors to adjust the $\mathrm{pH}$ value to 5.1. The details of the synthesis process can be found elsewhere ${ }^{7}$. The organic wet gels were then dried by supercritical $\mathrm{CO}_{2}$ for $6 \mathrm{~h}$ at $\mathrm{p}=12 \mathrm{MPa}$ and $\mathrm{T}=80{ }^{\circ} \mathrm{C}$. For comparison, a sample was also obtained by drying at ambient pressure for $4 \mathrm{~h}$. The dried aerogel samples were carbonised at $900{ }^{\circ} \mathrm{C}$ at a heating rate of $1{ }^{\circ} \mathrm{C} / \mathrm{min}$ for $6 \mathrm{~h}$ under a nitrogen atmosphere $\left(\mathrm{N}_{2}\right.$ flow rate $\left.=1.0 \mathrm{~L} / \mathrm{min}\right)$. The samples were then activated at $1000{ }^{\circ} \mathrm{C}$ for $1 \mathrm{~h}$ under a $\mathrm{CO}_{2}$ atmosphere $\left(\mathrm{CO}_{2}\right.$ flow rate $=$ $1.0 \mathrm{~L} / \mathrm{min}$ ). The $\mathrm{CA}$ samples are referred to as $\mathrm{CA}$ for a sample dried at ambient pressure and CA-SC for a sample dried with supercritical $\mathrm{CO}_{2}$.

The characterisation of carbon aerogels was carried out by different techniques. The microstructure of the material was observed by scanning electron microscopy (SEM), with a JMS-5310 microscope, from JEOL. For SEM analysis, the sample surface was previously coated with an $\mathrm{Au}$ film, by means of physical vapour deposition for $20 \mathrm{~s}$. The bulk density of the carbon aerogel was determined by weight-volume measurements of monolithic pieces of material. Textural characterisation of adsorbents was carried out by $\mathrm{CO}_{2}$ and $\mathrm{N}_{2}$ adsorption at zero and $-196{ }^{\circ} \mathrm{C}$, respectively and by mercury porosimetry. The DubininRaduskevich and BET equations were used for analysis of $\mathrm{CO}_{2}$ and $\mathrm{N}_{2}$ adsorption isotherms, respectively, with IQ2 (Quantachrome Inc., Boynton Beach, FL, USA). The liquid density of $\mathrm{CO}_{2}$ at $0{ }^{\circ} \mathrm{C}$ was taken as $1.03 \mathrm{~g} \mathrm{~cm}^{-3}$ and the molecular area of $\mathrm{N}_{2}$ at $-196{ }^{\circ} \mathrm{C}$ as $0.162 \mathrm{~nm}^{2}$. Mercury porosimetry was obtained up to a pressure of $4200 \mathrm{~kg} \mathrm{~cm}^{-2}$ with quantachrome autoscan 60 equipment. With this technique, the following parameters were obtained: pore volume corresponding to pores with diameter between 3.7 and $50 \mathrm{~nm}, \mathrm{~V} 2$, referred to as mesopore volume (note that mesopore volume range ${ }^{5}$ is classically defined as 2-50 nm); pore volume of pores with diameter greater than $50 \mathrm{~nm}$, or macropore volume, V3.

\section{Adsorption experiments}

\section{Determination of organic compound concentrations}

The adsorption capacity of carbon aerogel was determined in several steps. In this work, a UV-Vis spectrophotometer Genesys (Milton Roy Spectronic Genesys 5 Spectrophotometer) was used to determine the concentration of the organic compounds. The concentrations of benzene, hydroquinone, catechol and resorcinol used in the calibration curves were in the range of $0.002-0.2 \mathrm{~g} / \mathrm{L}$ and were analysed at wavelengths of $254 \mathrm{~nm}, 390 \mathrm{~nm}, 280 \mathrm{~nm}$ and $297 \mathrm{~nm}$, respectively.

\section{Adsorption equilibrium and kinetics}

Preliminary kinetic tests were carried out in order to determine the minimum contact time required to establish equilibrium conditions between the adsorbent (carbon aerogel) and adsorbates (benzene, hydroquinone, catechol and resorcinol). In these tests, an appropriate amount of adsorbent $(0.05 \mathrm{~g})$ and $50 \mathrm{~mL}$ of adsorbate solution with initial composition $0.2 \mathrm{~g} / \mathrm{L}$ were poured into $60 \mathrm{~mL}$ glass bottles. These flasks were agitated at $20 \mathrm{rpm}$ in a shaker (Themo scientific) at room temperature and samples for analysis were withdrawn after a certain contact time that varied between one and $120 \mathrm{~min}$. For the benzene, the preliminary tests showed that the adsorption equilibrium was reached within $60 \mathrm{~min}$. Owing to the moderate stirring speed used and because carbon aerogels were previously ground, further collapse of their structure was not noticeable to any significant extent. 
Equilibrium adsorption curves were obtained by mixing $0.05 \mathrm{~g}$ of adsorbent with $50 \mathrm{~mL}$ of solution containing adsorbate in different initial concentrations varying between 0.002 and $0.2 \mathrm{~g} / \mathrm{L}$. These experiments were carried out under the same conditions as those in the kinetic experiments (temperature and agitation) and in the optimum contact time of $60 \mathrm{~min}$.

\section{Theoretical models}

Adsorption isotherms describe how adsorbates interact with adsorbent materials and are fundamental in optimising the use of adsorbents. Thus, the correlation of equilibrium data using isotherm equations is important to the practical design and operation of adsorption systems. In study, Langmuir and Freundlich equations were tested. The Freundlich equation predicts that the concentration of adsorbate on the surface of the adsorbent will increase while increasing the concentration of the adsorbate in the liquid solution, following a power law as represented by

$$
\mathrm{q}_{\mathrm{e}}=\mathrm{K}_{\mathrm{f}} \mathrm{X} \mathrm{C}_{\mathrm{e}}{ }^{1 / \mathrm{n}}
$$

Where $\mathrm{q}_{\mathrm{e}}$ is the amount of adsorbate adsorbed per unit mass of adsorbent, $\mathrm{K}_{\mathrm{f}}$ is the Freundlich capacity factor, $\mathrm{C}_{\mathrm{e}}$ is the equilibrium concentration of adsorbate in the solution after adsorption and 1/n represents the Freundlich intensity parameter. The constants of the Freundlich isotherm were determined by linear regression, with the least squares method, applied to the experimental points and based on logarithmic linearisation. The Langmuir adsorption isotherm assumes the formation of a monolayer of adsorbate on the surface of the adsorbent and that all sites are equivalent. This isotherm is expressed as:

$$
q_{e}=\frac{a b c_{e}}{1+b C_{e}}
$$

Where $\mathrm{q}_{\mathrm{e}}$ is the amount of adsorbate adsorbed per unit mass of adsorbent, $\mathrm{C}_{\mathrm{e}}$ is the equilibrium concentration of adsorbate in solution, a represents the maximum adsorption capacity and $\mathrm{b}$ is the Langmuir constant that is a measure of the energy of adsorption. As regards the Freundlich model, the adsorption data were adjusted by linear regression, preceded by the linearisation of the Langmuir isotherm, which is represented as:

$$
\frac{C_{e}}{q_{e}}=\frac{1}{a b}+\frac{C_{e}}{a}
$$

The concentration of adsorbate retained in the adsorbent phase, $\mathrm{q}_{\mathrm{e}}(\mathrm{mg} / \mathrm{g})$, is calculated according to:

$$
q_{e}=\frac{V\left(C_{o}-C_{e}\right)}{m}
$$

Where $\mathrm{C}_{\mathrm{o}}$ and $\mathrm{C}_{\mathrm{e}}$ are the initial and the equilibrium concentrations ( $\left.\mathrm{mg} / \mathrm{L}\right)$, respectively, of adsorbate in solution, $\mathrm{m}$ is the mass $(\mathrm{g})$ of the adsorbent and $\mathrm{V}(\mathrm{L})$ is the solution volume.

\section{Results and discussion}

\section{Adsorbent characterisation}

\section{Morphology}

As can be seen in the SEM in Figure 1, the adsorbent material consists of a network of interconnected structural units. Thus, when the monolith is ground, the obtained particles of the adsorbent material are flakes but maintain the microstructure observed in the monoliths. Thus, it is expected that the flakes of the aerogels will have a more open structure than other porous solids as those of xerogels. 


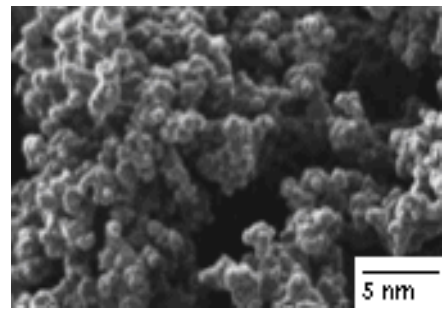

Figure 1. SEM of synthesised carbon aerogels

Figure 2 shows the adsorption and desorption isotherm of synthesised carbon aerogels. Hysteresis loops of the isotherm are usually attributed to capillary condensation occurring in mesopores. Non-vanishing of volumes adsorbed near zero relative pressure shown in the adsorption isotherm for carbon aerogels in Figure 2 indicates that some micropores exist in carbon aerogels. All the organic aerogels have a negligible amount of micropores. Figure 3 shows the pore size distribution of a carbon aerogel. As shown in Figure 3, micropores and mesopores are present in carbon aerogels as a result of synthesis.

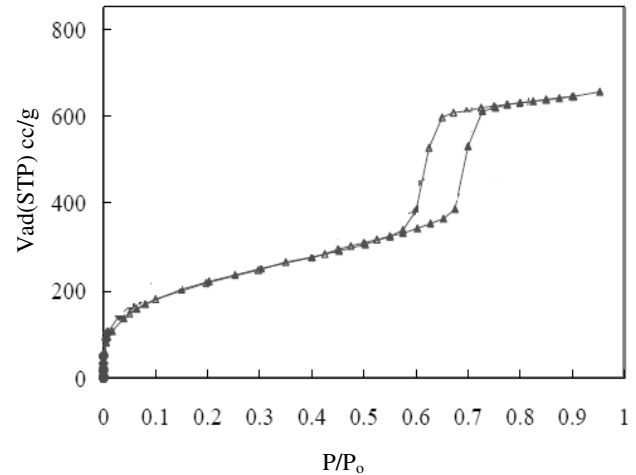

Figure 2. Adsorption and desorption isotherms of carbon aerogels.

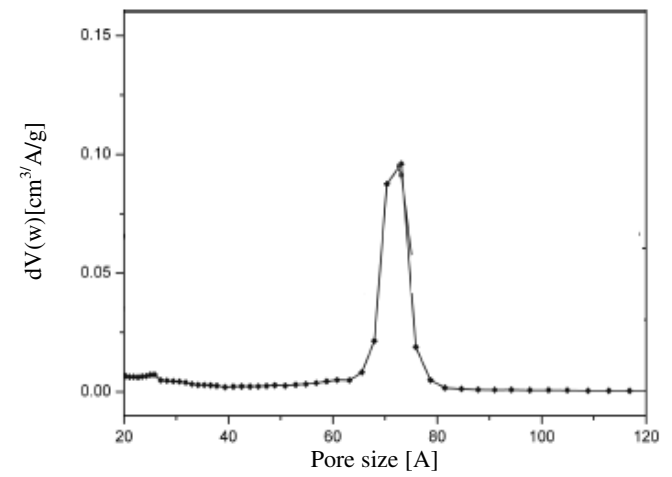

Figure 3. Pore size distribution of synthesised carbon aerogels

Thus, the carbon aerogels used in this work were characterised. The textural characteristics of samples are shown in Table 1.

Table 1. Textural characteristics of carbon aerogels and their benzene capacities (VTol) at saturation under static conditions and $25^{\circ} \mathrm{C}$

\begin{tabular}{ccccccc}
\hline Sample & $\mathrm{S}_{\mathrm{CO} 2}, \mathrm{~m}^{2} \cdot \mathrm{g}^{-1}$ & $\mathrm{~S}_{\mathrm{BET}}, \mathrm{m}^{2} \cdot \mathrm{g}^{-1}$ & $\mathrm{~L}_{\mathrm{o}}, \mathrm{nm}$ & $\mathrm{W}_{\mathrm{o}}, \mathrm{cm}^{3} \cdot \mathrm{g}^{-1}$ & $\mathrm{~V} 2, \mathrm{~cm}^{3} \cdot \mathrm{g}^{-1}$ & $\mathrm{~V}_{\mathrm{Benz}}, \mathrm{cm}^{3} \cdot \mathrm{g}^{-1}$ \\
\hline Aerog & 838 & 803 & 0.65 & 0.27 & 0.67 & 0.7 \\
\hline
\end{tabular}

The sample synthesised presented a large mesopore volume. In general, monomodal pore size distribution was obtained by mercury porosimetry ${ }^{3,4}$. The microporosity of the samples was studied by gas adsorption. The mean micropore width $\left(\mathrm{L}_{\mathrm{o}}\right)$, micropore volume $\left(\mathrm{W}_{\mathrm{o}}\right)$ and surface area accessible to $\mathrm{CO}_{2}\left(\mathrm{~S}_{\mathrm{CO} 2}\right)$ were obtained by applying ${ }^{5,14}$ the DR equation to $\mathrm{CO}_{2}$ adsorption isotherms and Eqs (5) and (6):

$$
\begin{gathered}
L_{o}(\mathrm{~nm})=\frac{10.8}{E_{o}(\mathrm{~kJ} / \mathrm{mol})} \\
S_{c o 2}=2000 \frac{W_{o}}{L_{o}}
\end{gathered}
$$


The mean micropore width obtained is 0.65 , whereas the micropore volume starts from $0.27 \mathrm{~cm}^{3} \mathrm{~g}^{-1}$. The widest micropores are a consequence of the methodology utilised for carbon aerogels synthesised in accordance with the literature. The values obtained for $\mathrm{S}_{\mathrm{BET}}$ and $\mathrm{S}_{\mathrm{CO} 2}$ are related to the method of synthesis, the temperature and the gas used in this case.

\section{Adsorption equilibrium}

The description of adsorption equilibrium data with the Langmuir and Freundlich isotherms (Eqs (1) and (2)) enabled us to evaluate the adsorption capacity of the adsorbent carbon aerogel for removing toxic organic compounds (benzene, hydroquinone, catechol and resorcinol). Experimental and calculated results plotted as concentrations of organic compounds adsorbed into aerogels, $\mathrm{q}_{\mathrm{e}}$, as a function of their equilibrium concentration in solution, $\mathrm{C}_{\mathrm{e}}$, are depicted in Figure $4 \mathrm{a}-\mathrm{h}$.

\section{Benzene}

\section{Langmuir model}

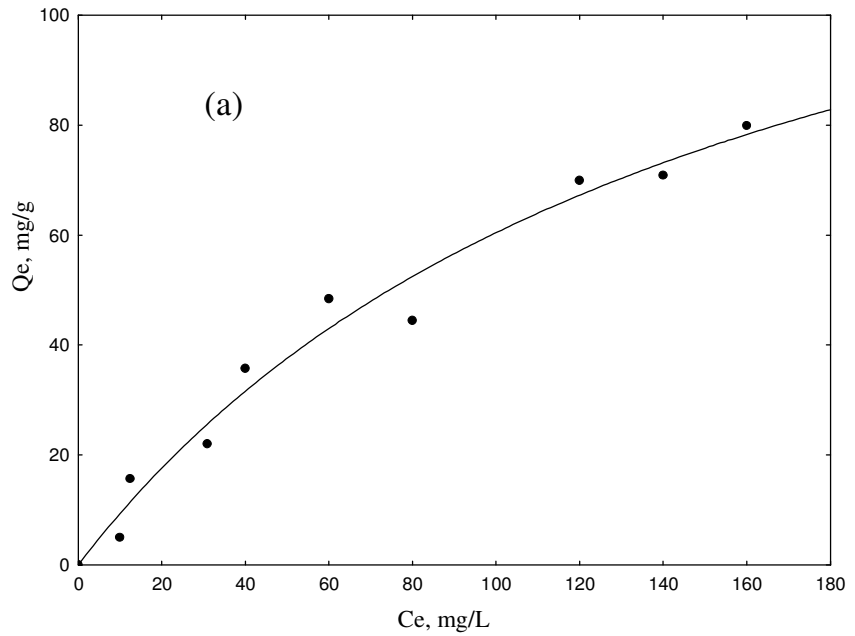

Freundlich model

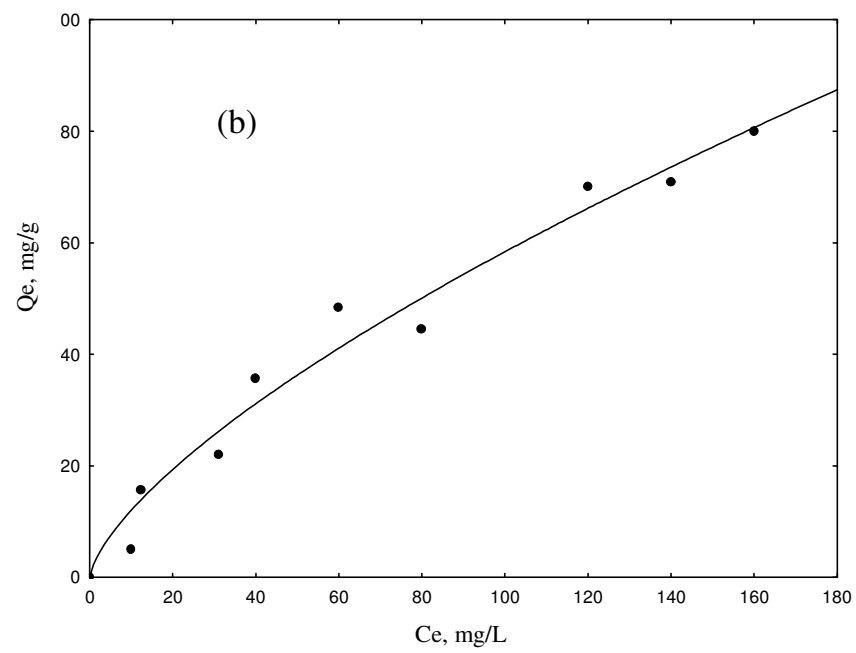




\section{Hydroquinone}

Langmuir model

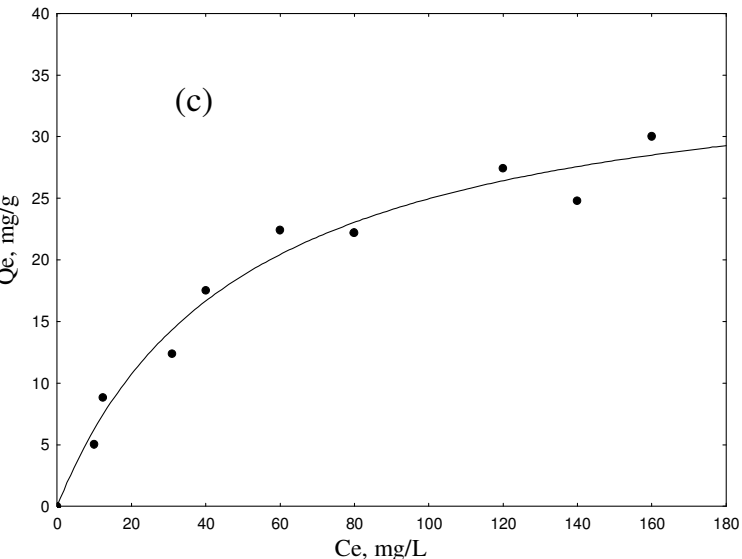

Freundlich model

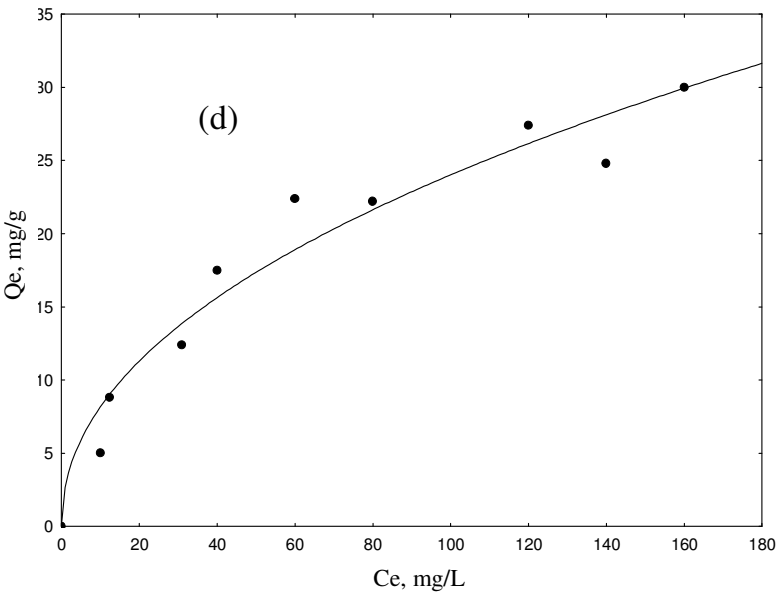

\section{Catechol}

Langmuir model

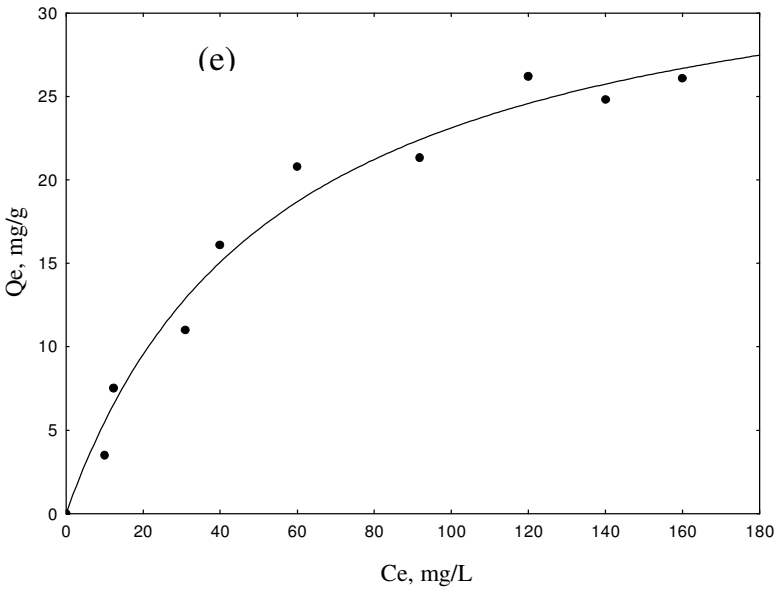


Freundlich model

\section{Resorcinol}

Langmuir model
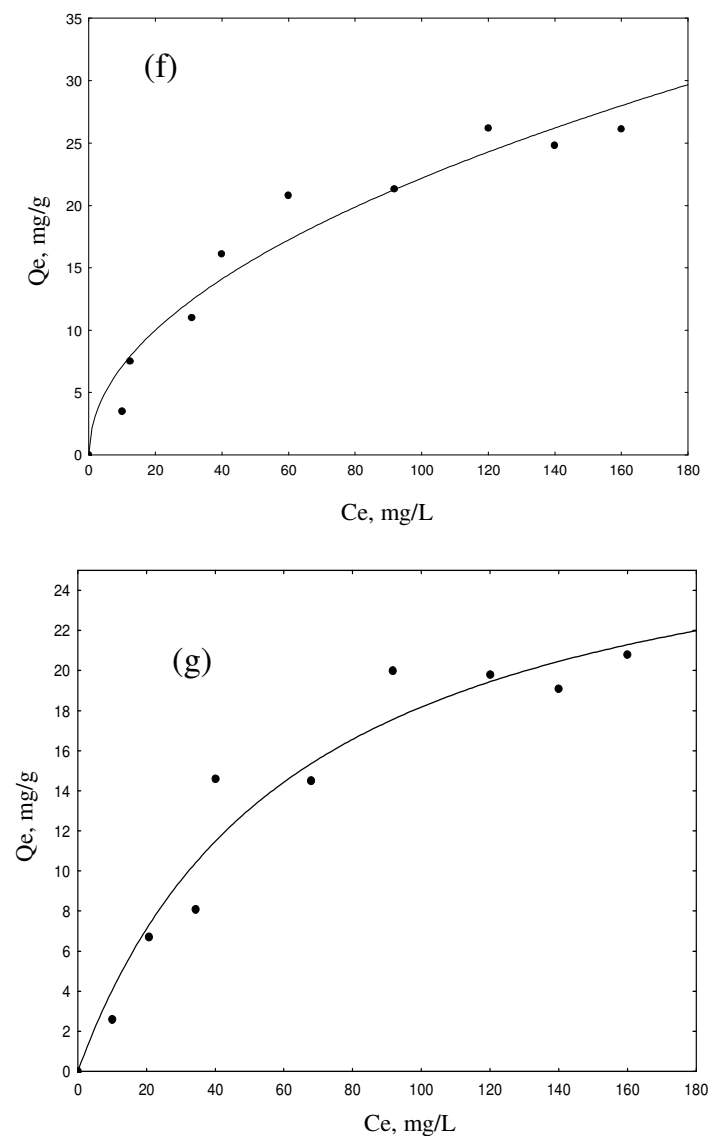

Freundlich model

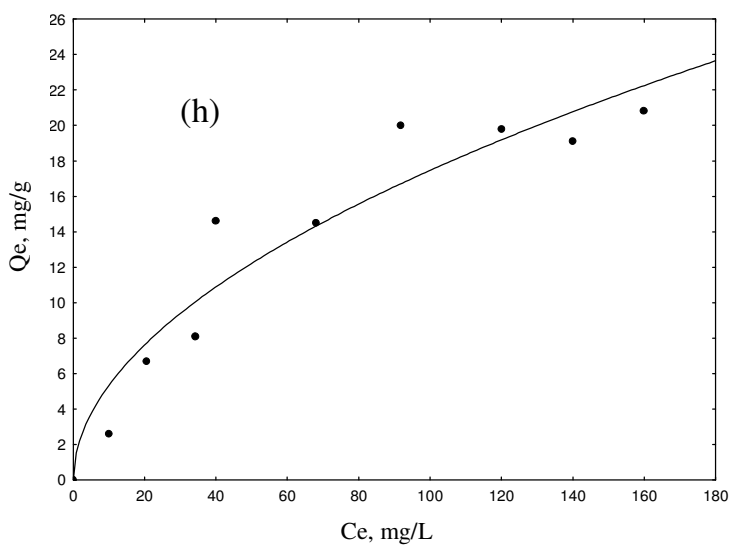

Figure 4. Langmuir and Freundlich models for benzene, hydroquinone, catechol and resorcinol respectively: (a) Benzene-Langmuir (b) Benzene-Freundlich (c) HydroquinoneLangmuir (d) Hydroquinone-Freundlich (e) Catechol-Langmuir (f) Catechol-Freundlich (g) Resorcinol-Langmuir (h) Resorcinol-Catechol 
On the basis of regression analysis of experimental data, it was possible to calculate the parameter values of the isotherms, as well as the correlation coefficients associated with each adsorbate/ adsorbent system (Table 2). As shown in the adsorption curves represented in Figure 4, the aerogels exhibit a good adsorption capacity for all adsorbates. The main reason for their higher adsorption efficiency is their highly porous structure. Indeed, this material was synthesised under supercritical conditions, which prevent pores from collapsing, contrary to what occurs in the case of other porous solids such as xerogels, for example.

Table 2. Parameter values of Langmuir and Freundlich isotherms

\begin{tabular}{cccccccc}
\hline Adsorbate & Adsorbent & \multicolumn{3}{c}{ Langmuir } & \multicolumn{3}{c}{ Freundlich } \\
\hline & & $\mathrm{a}$ & $\mathrm{bx10}$ & $\mathrm{r}^{2}$ & $\mathrm{k}_{\mathrm{f}}$ & $1 / \mathrm{n}$ & $\mathrm{r}^{2}$ \\
\hline Benzene & Aerogel & 242.33 & 1.24 & 0.995 & 2.23 & 0.79 & 0.985 \\
Hydroquinone & Aerogel & 32.44 & 0.75 & 0.976 & 0.00765 & 0.87 & 0.934 \\
Catechol & Aerogel & 27.54 & 0.65 & 0.986 & 0.00864 & 0.79 & 0.945 \\
Resorcinol & Aerogel & 21.45 & 0.83 & 0.956 & 0.00887 & 0.83 & 0.957 \\
\hline
\end{tabular}

Furthermore, the interaction between the hydrophobic surface of the carbon aerogel and the adsorbate molecules is different for each organic compound. As shown in Figure 4a and $\mathrm{b}$, benzene is seemingly well adsorbed. Differences in the adsorption capacity for a given adsorbent/adsorbate can be more accurately described, however, in terms of the maximum adsorption capacity values and the energy involved in the adsorption process. These parameters were determined by the Langmuir model and can be found in Table 2. Figure 4c shows that hydroquinone, catechol and resorcinol are adsorbed to a much lower extent by aerogel than benzene. In fact, hydroquinone, catechol and resorcinol are hydrophilic solvents and, therefore, owing to the super-hydrophobic nature of the adsorbent, there is a natural tendency for the solvents to be repelled by it. Moreover, hydroquinone, catechol and resorcinol are able to form hydrogen bonds with water molecules establishing in this way a strong interaction with the solvent which may enable its adsorption into the solid material. As previously mentioned, the parameters of the isotherms were obtained by fitting Eqs (1) and (2) to the experimental equilibrium data. The correlation coefficients shown in Table 2 indicate an adequate match of data with either Langmuir or Freundlich models in most cases. The higher value for the maximum adsorption capacity of the Langmuir model was observed for the case of adsorption of benzene into aerogel $(242.33 \mathrm{mg} / \mathrm{g})$. Conversely, the most promising results were obtained for toluene adsorption since this involves greater adsorption energy. The carbon aerogel adsorbents exhibited the lowest adsorption capacities for hydroquinone, catechol and resorcinol, i.e. $32.44 \mathrm{mg} / \mathrm{g}, 27.54$ and $21.45 \mathrm{mg} / \mathrm{g}$ for aerogel compared with other porous solids such as activated carbon; however, the results reported in this work for phenol derivatives are high compared with published results for phenol aerogels. This is a new result in this investigation. With regard to the Freundlich model, the $1 / \mathrm{n}$ values ranging between zero and one indicate a favourable adsorption isotherm for all case studies. The comparison of the results obtained in this work with those reported in the literature explains the importance of the adsorbent under study. Several adsorption isotherms for benzene using adsorbent materials of the aerogel and xerogel type can be seen in Figure $5^{20}$.

The results in Figure 5 clearly show that the materials used (aerogel-exp, xerogel-exp) exhibit better adsorption capacity than the MTMS-derived aerogels and TMES-derived aerogels reported in the literature for benzene adsorption ${ }^{20}$. The aerogels synthesised in this work were obtained from hexamethylenetetramine (HMTA), but their adsorption capacity differs greatly from that of the aerogels synthesised by Štandeker and co-workers ${ }^{20}$ with 
similar precursors. Thus, the discrepancies between the results obtained and those reported in the literature can be attributed to the preparation method which determined different pore structures of the synthesised materials. As aforementioned, the materials tested are characterised by bimodal distribution of micropores and mesopores. The synergetic effect between the macroscopic morphology and intrinsic pore connections between mesopore channels and micropores contributes to a large adsorption capacity ${ }^{20}$. In the case of the aerogels tested by Štandeker and co-workers, lower amounts of adsorbed benzene were found, which could be attributable to their pore structures essentially being based on micropores.

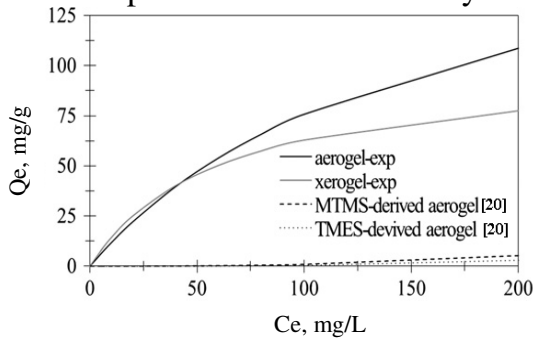

Figure 5. Comparison between experimental isotherms for benzene and those in the literature. $^{20}$

\section{Conclusion}

In this work, carbon aerogel materials were synthesised with hexamethylenetetramine (HMTA) as a chemical precursor to provide an efficient adsorbent for benzene from aqueous solutions. The aerogels synthesised developed a higher specific surface area and mesopores, favouring the adsorption of organic compounds on the surface of aerogels and leading to a greater adsorption capacity for benzene, hydroquinone, catechol and resorcinol compared with other porous solids described in the literature.

The carbon aerogels showed good adsorption capacity of hydrophobic compounds and non-polar, as benzene. For hydrophilic compounds, such as hydroquinone, catechol and resorcinol, the adsorption capacity was found to be low but are higher in compared with the adsorption of phenol on aerogels. Compared with other reported data, the aerogels that were prepared in this work showed a significantly greater adsorption capacity for benzene.

\section{Acknowledgement}

The authors wish to express their appreciation of the Master Agreement established between Universidad de los Andes de Colombia and Universidad Nacional de Colombia and the Memorandum of Understanding between the Departments of Chemistry of both universities. Special thanks go to the Fondo Especial de la Facultad de Ciencias and Proyecto Semilla of Universidad de los Andes for partial financial support of this research.

\section{References}

1. Banat F A, Al-Bashir B, Al-Asheh S and Hayajneh O, Environ Pollu., 2000, 107(3), 391-398.

2. Hameed B H and Rahman A A, J Hazard Mater., 2008, 160, 576-581.

3. Turhan K and Uzman S, Desalination, 2008, 229(1-3), 257-263.

4. Aksu Z and Yener J, Waste Management, 2001, 21(8), 695-702.

5. Rengaraj S, Moon S H, Sivabalan R, Arabindoo B, Murugesan V, Waste Management, 2002, 22(5), 543-548. 
6. Chern J M and Chien Y W, Water Res., 2003, 37, 2347-2356.

7. Nakagawa K, Namba A, Mukai S R, Tamon H, Ariyadejwanich P and TanthaPanichakoon W, Water Res., 2004, 38(7), 1791-1798.

8. Daifullah A A M and Girgis B S, Water Res., 1998, 32(4), 1169-1177.

9. Tan I A W, Hameed B H and Ahmad A L, Chem Eng J., 2007, 127(1-3), 111-119.

10. Hameed B H, Din A T M and Ahmad A L, J Hazard Mater., 2007, 141, 819-825.

11. Tan I A W, Ahmad A L and Hameed B H, J Hazard Mater., 2008, 154(1-3), 337-346.

12. Simitzis J and Sfyrakis J, J Appl Polym Sci., 1994, 54, 2091-2099.

13. Pekala R W, J Mater Sci., 1989, 24, 3221-3227.

14. Pekala R W, US Patent 4, 1989, 873, 218.

15. Pekala R W, US Patent, 1991, 997, 804.

16. Al-Muhtaseb S A and Ritter J A, Adv Mater., 2003, 15(2), 101-114.

17. Maldonado-Hódar F J, Ferro-García M A, Rivera-Utrilla J and Moreno-Castilla C, Carbon, 1999, 37(8), 1199-1205.

18. Maldonado-Hódar F J, Moreno-Castilla C and Pérez-Cadenas A F, Microporous Mesoporous Mater., 2004, 69(1-2), 119-125.

19. Tian H Y, Buckley C E, Paskevicius M and Wang S B, J Supercritical Fluids, 2011, 55(3), 1115-1117.

20. Štandeker S, Novak Z and Knez Z, J Colloid Interface Sci., 2007, 310(2), 362-368. 